\title{
Ultimate Capacity of Vertical Pile Subjected to Combination of Vertical and Lateral Load
}

\author{
Asim Goswami, Soumya Roy
}

\begin{abstract}
Pile under general condition is subjected to combination of vertical and lateral loads In the analytical approaches to predict the load-displacement responses of a pile under central inclined load, it is assumed that the lateral displacement of the pile head is independent by the vertical load factor of the inclined load. Similarly, while estimating the ultimate resistance it is considered that the vertical load factor of the inclined load does not influence the ultimate lateral resistance of the pile during determination of ultimate load carrying capacity of vertical pile. In the present work, an empirical relation has been developed to predict the ultimate load carrying capacity of vertical piles subjected to combination of both vertical and lateral load in cohesion less soil. Effect of lateral load on vertical load deflection behavior of vertical piles when axial loads are present are discussed through several experimental results obtained from tests on model piles. Ultimate capacity is found to be a continuous function of ultimate lateral load, ultimate vertical load capacity and tangent of angle of resultant load made with vertical axis of pile.
\end{abstract}

Keywords - Pile foundation; Ultimate vertical capacity; Lateral load on vertical pile;

\section{INTRODUCTION}

Foundations of many structures are subjected to inclined compressive loads like in foundations of transmission towers, wind energy converter towers, offshore structures etc. In such cases, to increase the load carrying capacities of adopted foundations and to decrease the corresponding settlements, piles may be employed. Besides, in the complex cases where the horizontal and vertical moments

Are generated along with the moments generated due to wind and seismic loads a pile foundation should satisfy the safety and serviceability conditions well. Normally the axial loading of the pile is predominant. But in special cases like piles supporting offshore wind energy foundations or conductors, the axial, mostly vertical load is accompanied by a lateral (horizontal) load as pointed out by Lianyang Zang et al. (2005).

Simplified methods to evaluate ultimate resistance under oblique pull have been attempted for vertical piles by Broms (1965), Meyerhof (1973), Poulos and Davis (1980), Chattopadhyay \&Pise (1986) and for inclined piles by Flemings et al. (1985).Bearing capacity of rigid piles based on $1 \mathrm{~g}$ experiments in sand and clay has been studied by Meyerhof et al. (1965 and 1961) 1g model test on vertical (1981b), batter piles (1972) and pile groups (1973) by Meyerhof et al. showed the variation of ultimate capacity

Revised Manuscript Received on July 18, 2019.

Asim Goswami, Assistant Professor, Department of Civil Engineering, Camellia Institute of Engineering and Technology, Budbud, Purba, Bardhaman, West Bengal-714155. (E-mail: asimgoswami1994@gmail.com)

Soumya Roy, Assistant Professor, Department of Civil Engineering, Meghnad saha Institute of Technology Kolkata, Kolkata, West Bengal 700150. (E-mail: roy.soummo@gmail.com) of model piles with load inclination. Several other results of investigations on the behaviour of piles subjected to inclined loading have been reported Das et al. (1976), Chari \& Meyerhof (1983), Ismael (1989),Sastry \& Meyerhof (1990), Shahrour \& Meimon (1991), Meyerhof (1995), Amde et al. (1997)and K.Abdel-Rahman \&Achmus (2006). However, the comparative study by Lianyang Zang etal. (2005) has shown that these studies produced significantly different ultimate resistance values of single as well as pile group. This makes it difficult for practicing engineers to effectively select the appropriate method.

Current design practice involves separate analysis of axial and lateral pile capacities and does not consider the interaction of vertical and horizontal load components in case of inclined loading conditions. As there are limited experimental studies available on behavior of vertical piles subjected to inclined compressive loads. In this paper, an attempt has been made to study behavior of single pile subjected to varying inclined load until failure through a $1 \mathrm{~g}$ model.

\section{WORK OBJECTIVE}

In the analytical approaches to predict the loaddisplacement responses of a pile under central inclined load, it is assumed that the lateral displacement of the pile head is independent by the vertical load factor of the inclined load. Similarly, while estimating the ultimate resistance it is considered that the vertical load factor of the inclined load does not influence the ultimate lateral resistance of the pile. The analytical approaches of K.Abdel-Rahman \&Achmus (2006), Poulos and Davis (1980), to predict the ultimate resistance of vertical pile are over simplified.

Reliability on any theoretical approach depends on agreement of estimated results with the experimental observations. However, for pile under inclined loads, very few test results are available.

The present work provides results of model vertical pile tested under controlled conditions for load displacement and ultimate resistance under central inclined compressive loads. Present work was intended to study the assumed simple but rather complex behaviour of a single pile-soil interaction mechanism under different inclined loading system.

\section{EXPERIMENTAL SETUP}

Dry brown uniformly graded Mogra sand obtained from sand mines of Hoogly district, West Bengal was used as soil medium. The physical properties of the sand are given in Table-1. 


\section{ULTIMATE CAPACITY OF VERTICAL PILE SUBJECTED TO COMBINATION OF VERTICAL AND \\ LATERAL LOAD}

Rigid rough mild steel circular cross section having outside diameter $20 \mathrm{~mm}$ and wall thickness $5 \mathrm{~mm}$ with three types of length to ratio viz. 10, 15, 20 were used as model piles. Surface of the pile is made rough by scratching the surface with iron paper followed by gluing mild steel powder carefully so that the outside diameter of the piles remain same as described in Chattopadhyay and Pise (1986). Procedure of the tests has been discussed elsewhere Roy et al. (2013). Pile is installed as fully embedded in sand bed.

The tests were conducted in a steel tank of size $100 \mathrm{~cm} \mathrm{X}$ $100 \mathrm{~cm}$ and $75 \mathrm{~cm}$ deep. Loads were applied on the top of the pile with load inclined at an angle $(\theta) 0^{0}, 15^{\circ}, 30^{\circ}, 45^{\circ}$ and $90^{\circ}$ with the vertical axis of the pile. A schematic view of the experimental assembly is shown in Fig.1.Details of the test procedure are described elsewhere (Roy et al. 2012).

Table 1 Physical properties of sand

\begin{tabular}{cc}
\hline Soil & Sand \\
\hline $\boldsymbol{\rho m a x}(\mathbf{g m} / \mathbf{c c})$ & 1.545 \\
\hline $\boldsymbol{\rho}$ min $(\mathbf{g m} / \mathbf{c c})$ & 1.431 \\
\hline $\mathbf{C u}$ & 1.25 \\
\hline $\mathbf{C c}$ & 0.96 \\
\hline $\boldsymbol{\varphi}^{\circ}$ & 39 \\
\hline $\mathbf{D 1 0}(\mathbf{m m})$ & 0.45 \\
\hline Specific Gravity & 2.65 \\
\hline Relative Density & $65 \%$ \\
\hline Classification & Medium Dense \\
\hline
\end{tabular}

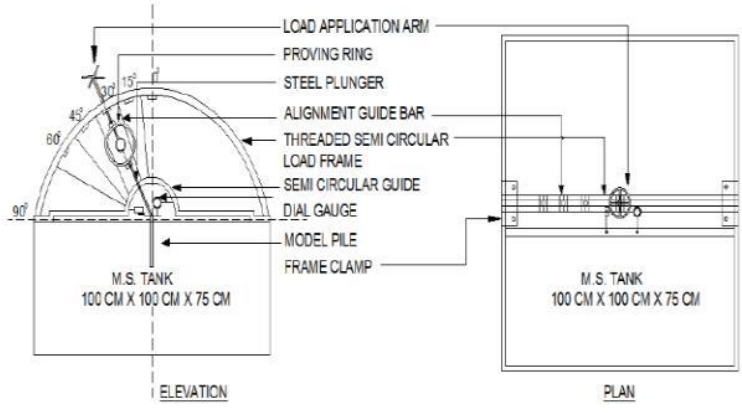

Fig. 1 Elevation and Plan of Experimental Setup (Roy et. al 2012)

\section{EXPERIMENTAL RESULTS AND DISCUSSION}

When the applied load is inclined at an angle $\theta$ with the vertical, ultimate load of pile is denoted by, P $\theta$ and the ultimate resistance of the pile in case of purely axial load and purely lateral load is denoted by $\mathrm{PU}$ and $\mathrm{PH}$ respectively as shown in Fig. 2. Due to application of oblique load $\mathrm{P} \theta$ on a pile, it is subjected to a vertical component, $\mathrm{Pv}$ and a horizontal component, $\mathrm{Ph}$. These components were expressed as

$$
\begin{aligned}
& \mathrm{PV}=\mathrm{P} \cos \theta \\
& \mathrm{Ph}=\mathrm{P} \sin \theta
\end{aligned}
$$

Where, $\mathrm{q}$ is the load inclination from vertical with axis of the pile. From Eqn. (1) and Eqn. (2) it is seen that as $\Theta$ increases, $\mathrm{Pv}$ decreases and $\mathrm{Ph}$ increases. Thus with the increase of tilt of load with the vertical direction the horizontal component dominates the vertical load component.
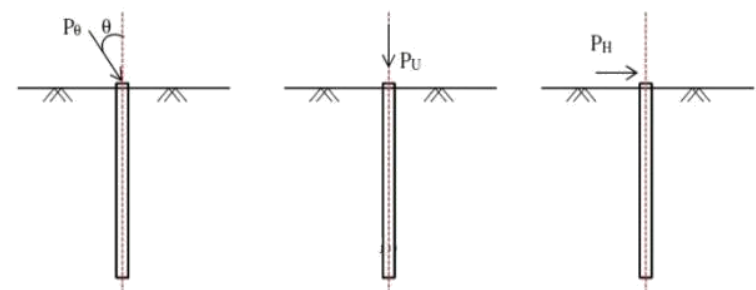

\section{Fig. 2 Pile under different loading condition and notations}

As the applied compressive load increases, at an angle of inclination, both the vertical as well as horizontal component of the load increases. Depending on the relative magnitudes of the ultimate axial capacity and lateral ultimate resistance of the pile, the vertical component may attain critical value equal to ultimate load carrying capacity of pile axially. In this case, the horizontal component remains smaller than the ultimate horizontal load carrying capacity causing axial failure of the pile. However, if the horizontal component reaches the critical value equal to the ultimate horizontal capacity, while the axial component is less than the ultimate axial load capacity, plastic hinge formation takes place and bending failure will occur. To permit reuse of the test piles, short rigid mild steel pile was selected.

\section{LOAD VERSES DISPLACEMENT DIAGRAMS}

Fig. 3a, 4a, shows the vertical displacement of pile having $\mathrm{L} / \mathrm{d}=20$ and 15 under various inclination of load with the pile axis, where $\mathrm{d}$ is the pile diameter and $\mathrm{L}$ is the length. Failure was associated with noticeable peak values for $\theta=$ $0^{0}$ and $\theta=15^{\circ}$. However, for greater values of $\mathrm{q}$, failure load were obtained where load settlement curves becomes almost vertical. The vertical load displacement curve patterns obtained are similar to those as reported by Meyerhof et al. (1983).

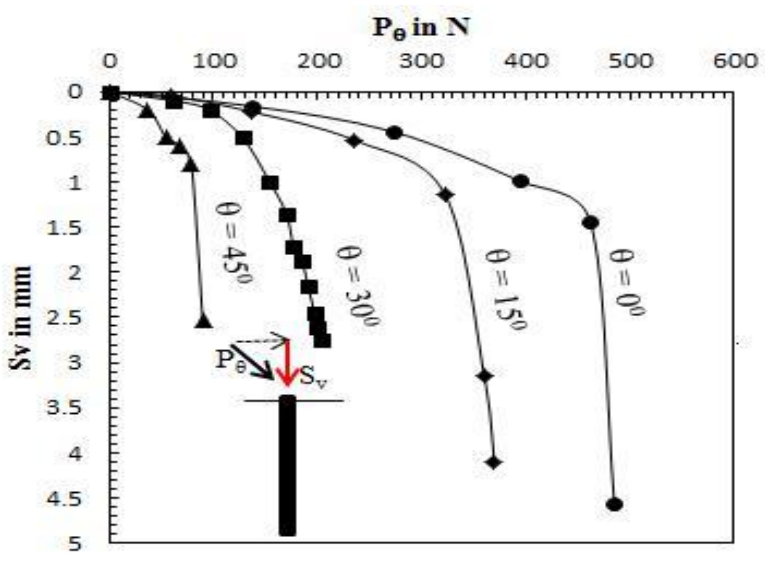

(a) Axial Displacement

Published By: 


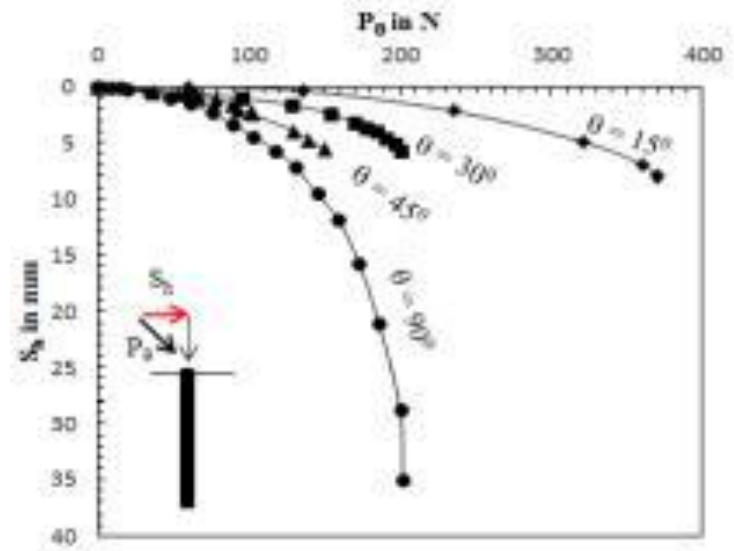

(b) Lateral Displacement

Fig. 3 Load versus displacement of pile $(d=20 \mathrm{~mm}, L=$ $400 \mathrm{~mm}$ )

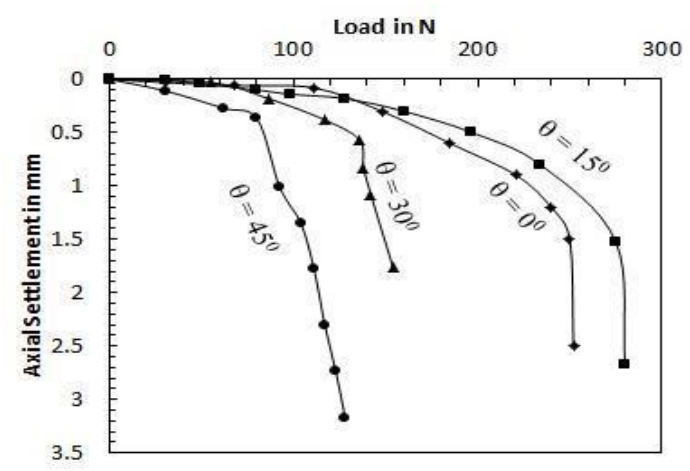

(a) Axial displacement

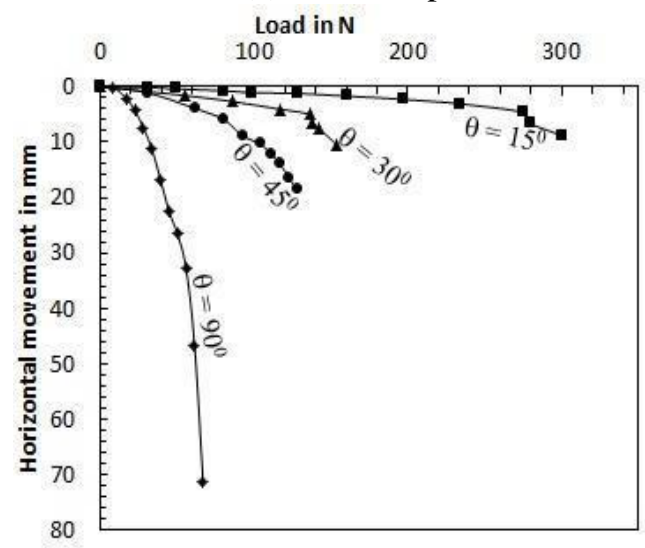

(b) Lateral displacement

Fig. 4 Load versus displacement of pile $(d=20 \mathrm{~mm}, \mathrm{~L}=$ $300 \mathrm{~mm})$

\section{ULTIMATE LOAD BEARING CAPACITY OF PILE UNDER INCLINED LOAD}

Failure of pile is considered at the load where associated load settlement curves become close to vertical. A polar plot of ultimate load on pile versus load inclination, $\theta$ is shown in Fig. 5 to show the inclination effect of the applied load on pile capacity. To quantify the effect in bearing capacity with the increase in load inclination angle $\theta$, ratio of $\mathrm{Pv} / \mathrm{PU}$ is plotted with different values of $\theta$ as shown in Fig. 6 for $\mathrm{L} / \mathrm{d}$ ratio of 20 and 15 .

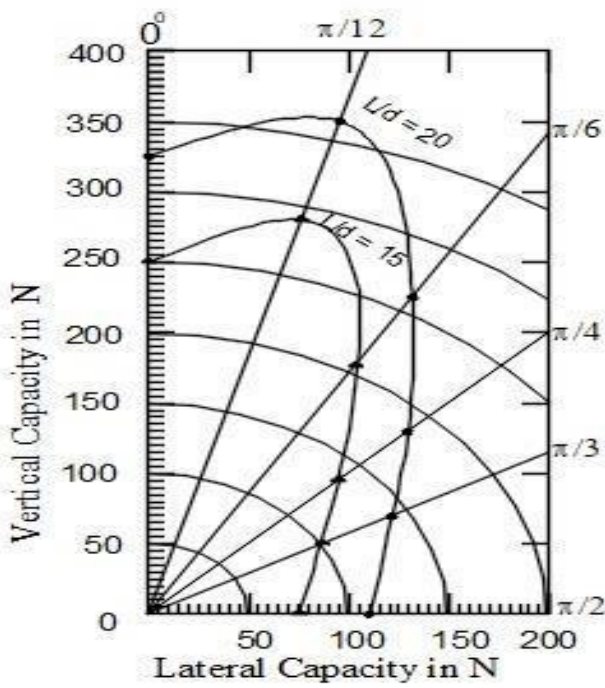

Fig. 5 Polar bearing capacity (Roy et. al 2013)

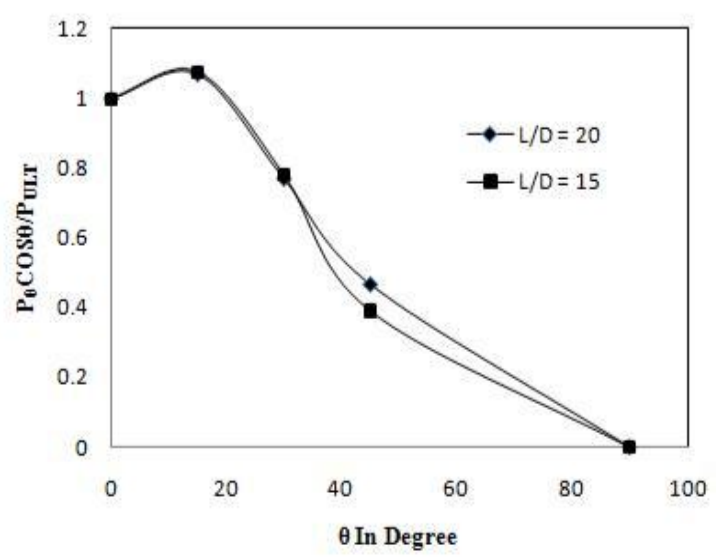

Fig. 6 Capacity of pile with load inclination

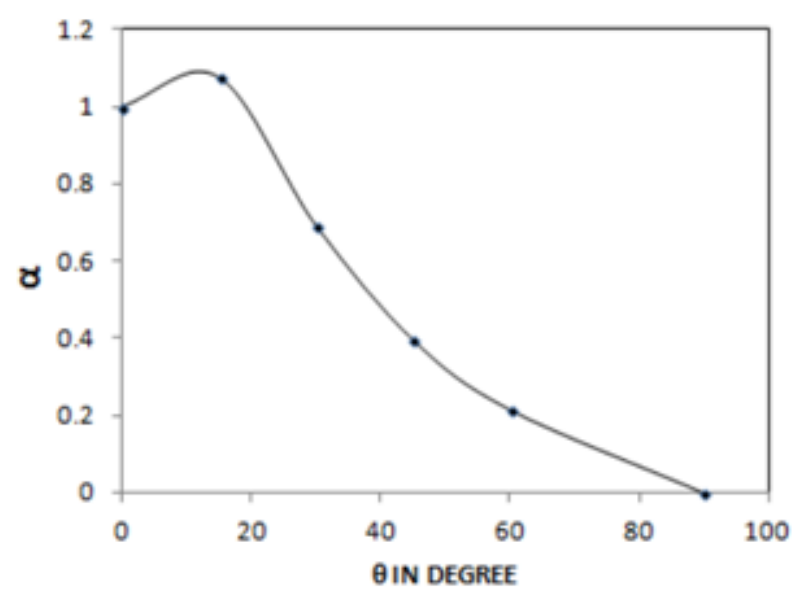

Fig. $7 \alpha$ vs $\theta$ plot 


\section{ULTIMATE CAPACITY OF VERTICAL PILE SUBJECTED TO COMBINATION OF VERTICAL AND}

\section{LATERAL LOAD}

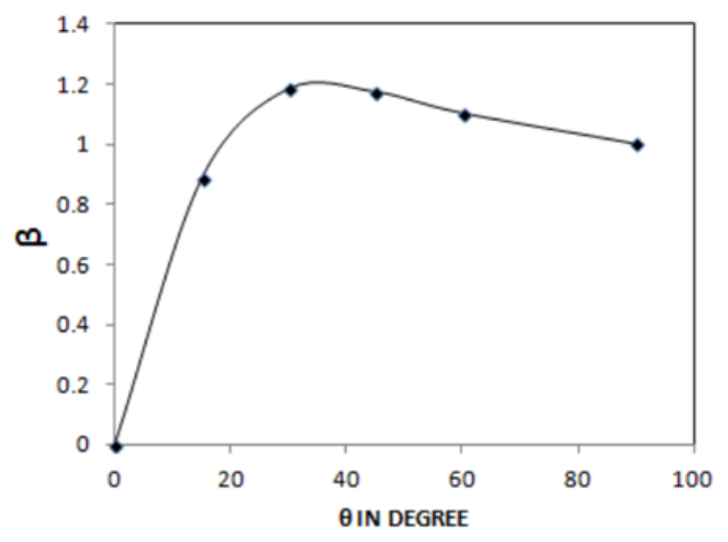

Fig. $8 \beta$ vs $\theta$ plot

Where, $\quad \frac{P \cos }{P}$ and $\frac{P \sin }{P}$

()$C^{3} C^{2} C C$

1

2

3

4

Hult

\section{A. Developed Empirical expression}

Based on the test results conducted, the polar plot is done with ultimate capacity of vertical pile for different $\theta$.An empirical expression is developed from the polar plot between Pvult and PHult, $\mathrm{P} \theta$ and $\theta$ in medium dense sand given by Eqn. (3) and (4) respectively .
$A^{3}$
1
$A^{2}$
A1
$B^{3}$
$1 \quad B^{2}$
2
B

By doing Eqn. (3) + Eqn. (4) one gets ,

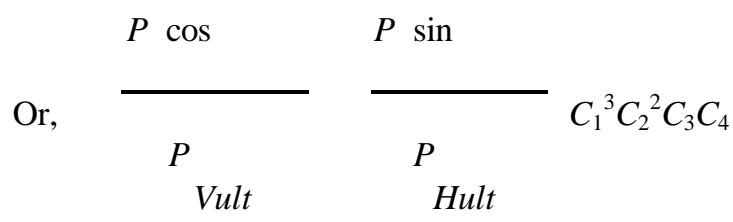

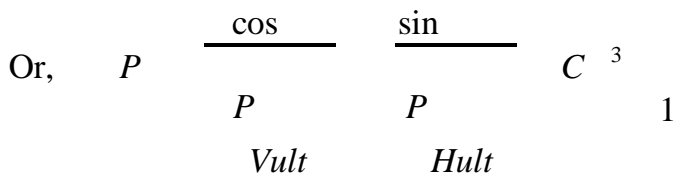

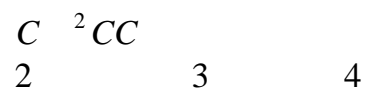

(6)

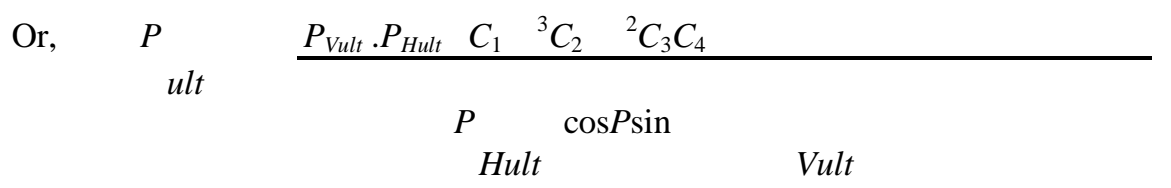

\section{DESIGN PROCEDURE}

For design purpose the maximum vertical and lateral load that will be imposed on the structure including the earthquake and wind load consideration are required. For that purpose one may create STAAD PRO. Model or any other software or use hand calculation for finding the maximum vertical and lateral load.

The latter stage of this designing concept are described stepwise-

Step-01: Calculate the maximum vertical and maximum lateral load that will come on the structure. For one structure different footing subjected to different load but the maximum of vertical and lateral load will be taken. 
Step-02: After findings of maximum vertical and lateral load such as PV and PH respectively then calculate the angle

${ }_{1}$ with the following
$P^{V}$

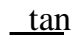

$$
P_{H}
$$

Step-03: After finding the $\theta$ value the value of critical angle have to be calculated by the following empirical relation Critical angle $=\left(90^{\circ}-\Theta\right)$

One pictorial representation is shown in the fig 9 below to demonstrate the different load components of pile also demonstrate the different angles like inclination angle and critical angle.

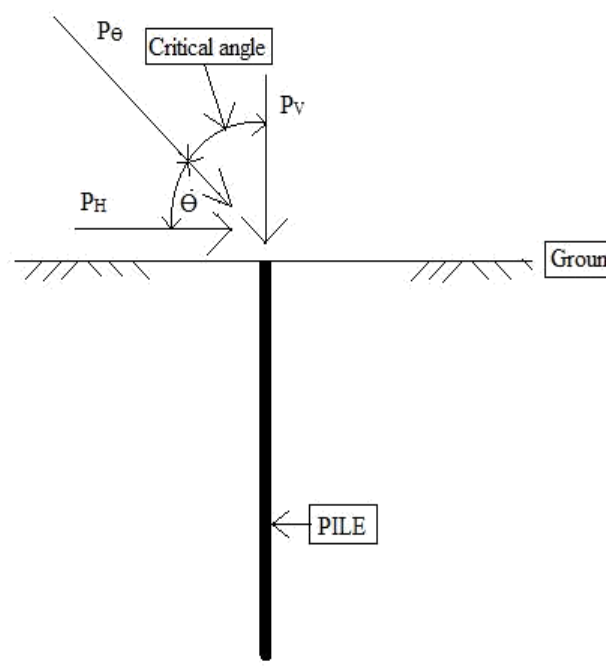

Fig. 9 Pile under different load components

Critical angle is that angle beyond which if the resultant of vertical and lateral load will act that results either failure of pile model or a significant change in the value of the ultimate pile capacity with some lesser value.

The value of this critical angle is found to lie in between $1^{0}$ to $22^{0}$ it was found by experimentally and the same value will getting by solving analytical problems. If we change the diameter, sub soil condition and all others parameters the value of this angle will remain same to confirm these we have run one excel program by changing different values of diameter, angle of internal friction and the unit weight of soil also that results the same.

To confirm this we will run different STAAD PRO model but the model gives the same results. So it is confirm that the critical angle value lies in between $1^{0}$ to $20^{0}$.

That value is the actual value of load considering for design purpose, after that moment will change those moment was found by only vertical or only lateral consideration and the design of pile foundation are most convenient.

\section{CONCLUSIONS}

An empirical relation is proposed for determination of ultimate load carrying capacity of vertical pile in medium dense sand subjected to combination of vertical and lateral load acting on pile head.

Several tests on the model pile under different inclined load in sand revealed that an inclination of load could noticeably reduce the ultimate vertical bearing capacity of short pile and lateral capacity of a vertical pile.

The load vertical displacement and load lateral movement of pile head in direction of load characteristics is nonlinear in nature.

Polar bearing capacity diagrams suggests that bearing capacity of vertical pile is a function of applied load inclination angle, $\theta$, vertical pile capacity, Pvult and ultimate lateral load carrying capacity of vertical pile. Phult

Determination of ultimate bearing capacity of vertical pile subjected to load combination of vertical and lateral load would be under safe if one or the other component $\mathrm{P}$ $\cos \theta$ or $\mathrm{P} \sin \theta$ is neglected or assumed to be zero for predicting ultimate capacity of a vertical pile subjected to a general loading condition.

\section{REFERENCES}

1. Amde, A.M., Chini, S.A. \& Mafi, M. 1997. Model study of H-piles subjected to combinedloading. Geotechnical and Geological Engineering, Vol. 15, pp. 343-355.

2. Broms, B.B. 1965. Discussion to paper by Y. Yoshimi., Journal of Soil Mechanics and Foundation Engineering Division, ASCE, Vol. 91, No.4, pp 199-205.

3. Chattopadhyay, B.C. \&Pise, P.J., 1986. Ultimate Resistance of Vertical Piles to Oblique Pulling Loads, Proc. 1st East Asian Conference on Structural Engineering and Construction, Bangkok,pp 1632-1641.

4. Das, B.M., Seeley,G.R.\& Raghu, D. 1976. Uplift Capacity of Model Piles under Oblique Loads. Journal of the Geotechnical Engineering Division, ASCE, Vol. 102, No. (9), pp. 1009-1013.

5. Ramanathan, T.S. \&Aiyer, P.G., 1970. Pull out Resistance of Piles in Sand, Journal of Indian National Society of Soil Mechanics and Foundation Engineering, Vol. 9. No. 2, pp 189-202.Poulos, H. G., and Davis, E. H., 1980. Pile Foundation Analysis and Design, John Wiley, New York.

6. Burland and Lord (1970), "Depth Correction Factor for Settlement of a Deep Foundation" Journal of Soil Mech. \& Foundation Division ASCE, Vol. 86, Pp. 57-61.

7. Matlock, H. and Reese, L. C., (1970), "Generalized solutions for laterally loaded piles", Journal of Soil Mech. \& Foundation Division ASCE, Vol. 86, Pp. 63-91.

8. H. G., and Davis, E. H., 1980. Pile Foundation Analysis and Design, John Wiley, NewYork

9. Vesic A.B (1961), "Beams on Elastic subgrade and Winkler's Hypothesis", Proc. $5^{\text {th }}$ Int. Conf. Soil mechanics and foundation engineering, paris

10. Brrezantav, V.G (1961), " Load bearing capacity and deformation of piled foundation" , Proc. $5^{\text {th }}$ ICSMEF, 2, Paris

11. Roy, S., Chattopadhyay, B.C., \& Sahu, R.B., 2012. Load Deformation Characteristics of Circular Raft-Pile Combination Subjected to Oblique Loadings, Proc. Indian Geotechnical Conference, Delhi, India, Vol. 1, pp 532-535. 
12. Roy, S., Chattopadhyay, B.C., \&Sahu, R.B., 2013. Pile Behaviour under Inclined Compressive Load- A Model Study, EJGE, Vol. 18, pp 2187-2205.

13. Sastry, V.V.R.N. \& Meyerhof, G.G. 1990. Behaviour of flexible piles under inclined loads. Canadian geotechnical Journal, 27(1), pp. 19-28.

14. Yoshimi, Y. 1964. Piles in Cohesion less Soil subject to Oblique Pull. Journal of the Soil Mechanics and Foundations Division, ASCE, 90(6), pp. 11-24.

15. Fleming, W. G. K., Weltman, A. J., Randolph, M. F. \& Elson, W.K., (1985). Pilling Engineering, Survey University Press, Glasgow and London.

16. Ismael, N.F. 1989. Field Tests on Bored Piles Subject to axial and Oblique Pull. Journal of Geotechnical Engineering, Vol. 115, No. 11, pp. 1588-1598.

17. Terzaghi et all (1996) "evaluation of coefficient of subgrade reaction" Institute of engineers, London, Vol. 5, No 4.

18. Broms, B.B. 1964. Discussion to paper by Y. Yoshimi., Journal of Soil Mechanics and Foundation Engineering Division, ASCE, Vol. 21, No.3, pp 126-157.

19. Meyerhof, G.G (1976), "Bearing capacity and settlements of pile foundation", Journal of the geotechnical engineering Division, ASCE, Vol. 102, No. GT3

20. K. J. Bentley and M. H. E. Naggar, "Numerical analysis of kinematic response of single piles," Canadian Geotechnical Journal, vol. 37, no. 6, pp. 1368-1382, 2000. 